TAO, Vol. 16, No. 5, 1163-1176, December 2005

\title{
Interdecadal Changes in Heavy Rainfall in China during the Northern Summer
}

\author{
Chang-Hoi Ho ${ }^{1, *}$, Joo-Hong Kim ${ }^{1}$, Ka-Ming Lau ${ }^{2}$, Kyu-Myong Kim ${ }^{3}$, Daoyi Gong ${ }^{4}$, and Yun-Bok Lee ${ }^{1}$
}

(Manuscript received 15 October 2004, in final form 18 August 2005)

\begin{abstract}
Using ground observations of daily rainfall over China during summer (June - August) for the period 1961 - 95, we examined interdecadal changes in the distribution of rainy events as a function of the rain rate and assessed their contributions to the total summer rainfall. We found that central China was wetter, and northern and southern China were drier in the decades following 1979 as compared to the earlier decades. The interdecadal changes in the Chinese summer rainfall are closely linked to those in large-scale circulations: the southward displacement of a westerly wind at the levels of 200 and $850 \mathrm{hPa}$ over East Asia and an enhanced $850 \mathrm{hPa}$ northerly wind over central-eastern China. The corresponding $850 \mathrm{hPa}$ relative vorticity increased (decreased) over central (northern and southern) China where the summer rainfall has increased (decreased) during the later decades. Interestingly, the change in the total number of rainy events was found to be negligible during the entire period of data collection. Across the overall region (mostly eastern China), a large amount of interdecadal changes is accounted for by less than $20 \%$ of the total number of rainy events in the heavy-to-extremely-heavy categories $\left(\geq \sim 25 \mathrm{~mm} \mathrm{day}^{-1}\right)$. The possible causes-associated with large-scale circulations-and the implications of the present results are discussed.
\end{abstract}

(Key words: Interdecadal changes, Heavy rainfall, East Asian summer monsoon,

China, Large-scale circulation)

\footnotetext{
${ }^{1}$ School of Earth and Environmental Sciences, Seoul National University, Seoul, Korea

2 Laboratory for Atmosphere, NASA/Goddard Space Flight Center, Greenbelt, MD, USA

${ }^{3}$ Science system and Applications, Inc., Lanham, MD, USA

${ }^{4}$ Key Laboratory of Environmental Change and Natural Disaster, Institute of Resources Science, Beijing Normal University, China

* Corresponding author address. Prof. Chang-Hoi Ho, School of Earth and Environmental Sciences, Seoul National University, Seoul, Korea; E-mail: hoch@cpl.snu.ac.kr
} 


\section{INTRODUCTION}

Many previous studies have demonstrated that the summer (June, July, and August) rainfall in China has undergone long-term changes (e.g., Yatagai and Yasunari 1994; Xue 1996; Nitta and Hu 1996; Weng et al. 1999; Gong and Ho 2002; Wang et al. 2004; Li et al. 2004). Over central China along the Yangtze River valley, a significant shift demonstrating an increase in the summer rainfall during the late 1970s (Gong and Ho 2002) is noteworthy. Increasing occurrences of flood events have been reported over the regions associated with enhanced rainfall since 1990 (e.g., 1991, 1996, 1998, and 1999) (Kun 2005). On the contrary, over northern and southern China, a decrease in summer rainfall was observed during the late 1970s. Importantly, the decreased rainfall over northern China is associated with a process of desertification in the arid and semi-arid regions (Xue 1996).

The interdecadal variations in summer rainfall are linked to changes in large-scale circulations associated with the East Asian summer monsoon (EASM). Zhu and Wang (2002) documented that the summer rainfall in northern China is greater than normal and that drought occurs along the middle-lower Yangtze River valley when the EASM is close to normal or weak. The large-scale factors controlling the EASM are known to be the strength and location of the North Pacific subtropical high, the East Asian upper tropospheric jet stream, and the Inter-tropical convergence zone (Lau et al. 2000; Li et al. 2004). Therefore, changes in largescale circulation modulate convective activities, which in turn modify the intensity of rainfall and the number of rainy days. Indeed, an increasing (decreasing) trend in rainfall for a given time period may manifest as either a change in the number of rainy events or the rain rate, or changes in both the measures. In the present study, we analyzed the frequency of rainy events and accumulative rainfall to investigate the contribution of various rain intensities to the interdecadal changes in the Chinese summer rainfall.

The daily rainfall data of 164 stations used in this study are obtained from the National Climate Center of China. Although the data are available for the period 1951 - 95, many data for the period prior to 1961 are missing in most stations of southeastern China. Therefore, we focused on the period (1961 - 95) for which more reliable observation data were available. In the present study, some atmospheric variables are taken from the 40-year reanalysis (ERA-40) from the European Centre for Medium-Range Weather Forecasts (ECMWF) for the same period (Uppala 2002). The ERA-40 used in this study covers a period from September 1957 to August 2002. The atmospheric variables used here include the zonal wind at $200 \mathrm{hPa}$ as well as zonal and meridional winds and relative vorticity at $850 \mathrm{hPa}$.

\section{INTERDECADAL CHANGES IN SUMMER RAINFALL AND RELEVANT LARGE-SCALE CIRCULATION}

In order to clarify the spatial and temporal variations in summer rainfall, an empirical orthogonal function (EOF) analysis is applied to the total Chinese summer rainfall data. The method is effective in identifying leading modes in temporal varying spatial patterns (eigenvectors) and their corresponding principal components (time series) and ranking them 
according to the percentage of total variance explained in the data of interest. Figure 1 shows the eigenvector (1a) and time series (1b) of the leading EOF mode, which explains $15.2 \%$ of the total variance. The spatial distribution of the eigenvector presents a meridionally banded structure over China (Fig. 1a). This structure indicates that the variations in summer rainfall in northern and southern China are in phase with each other but are out of phase with the variation in central China. The corresponding time series (Fig. 1b) shows a regime shift during the late 1970s, which is explicitly seen in the low-pass filtered time series (thick solid line). This regime shift is statistically significant at the $99 \%$ confidence level.

Meanwhile, a strong year-to-year variation is also observed. In other words, the dominant structure of variations in the summer rainfall may be consistent in both the interdecadal and interannual time-scales. In order to clarify this argument, we applied an additional EOF analysis to the rainfall data after eliminating the interdecadal changes (figure not shown). The result shows a nearly identical spatial structure of the eigenvector; thus, the meridionally banded structure shown in Fig. 1a is the most significant variation in the summer rainfall in both the interdecadal and interannual time-scales. This does not appear unexpected because Shen and Lau (1995) investigated the biennial oscillation signal in summer rainfall over the Yangtze River valley, which shows a pattern similar to the present result.

Combining the spatial distribution of the eigenvector and the associated time series of the leading EOF mode, there was a significant increase in the summer rainfall over central China and a decrease over northern and southern China during the late 1970s. Gong and Ho (2002)

\section{EOF $1^{\text {st }}$ mode $(1961-1995)$}

(a) Eigenvector (15.2\%)

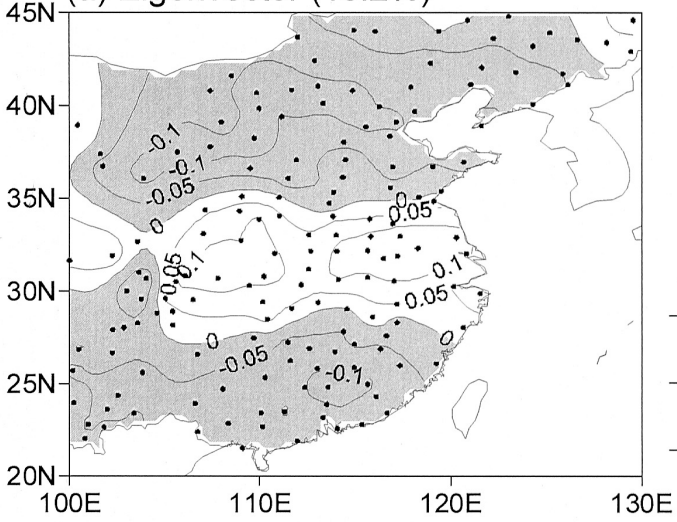

(b) Associated time series

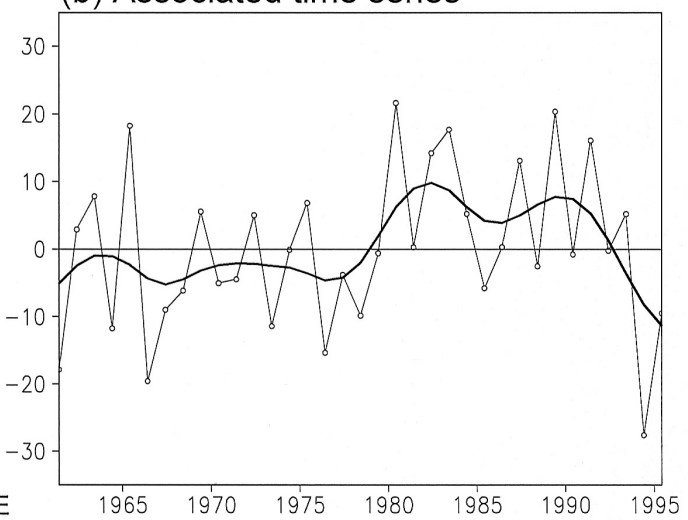

Fig. 1. Eigenvector (a) and associated time coefficient (b) of the leading EOF mode of the summer (June, July, and August) rainfall over China. Small dots denote all 164 stations. Negative values are shaded. Units are arbitrary for eigenvector and $\mathrm{mm} \mathrm{day}^{-1}$ for time coefficient. 
documented the fact that summer rainfall over the Yangtze River valley (central China) experienced a regime shift toward a wetter climate since 1980. Zhu and Wang (2002) analyzed the summer rainfall coded levels data for the period 1470 - 1999 and found a distinct 80-year oscillation signal. Interestingly, the last change in the sign of the oscillation occurred during the late 1970s. Wang et al. (2004) and Li et al. (2004) found that interdecadal changes had occurred several times in the Chinese rainfall, as recorded in the historical data for the last 100 years. Consistent with the present study, an abrupt change that occurred during the late 1970s is also shown in their results.

It should be noted that an abnormal negative peak is found in 1994 in the time series (Fig. 1b). In the summer of 1994, there was a severe drought over Korea and Japan; thus, this situation was not confined to central China alone. Yoo et al. (2004) suggested that the 1994 summer drought was caused by anomalously warm sea surface temperatures during the previous winter and spring over the tropical western North Pacific. The detailed mechanisms are documented in their paper along with a series of climate model simulations.

Li et al. (2004) reviewed the interdecadal variations in the Chinese climate in conjunction with large-scale variations in the global context, such as global warming, the East Asian monsoon, the North Atlantic Oscillation, and the North Pacific Oscillation. In the present study, however, we narrow down the area of focus to the Asian continent and the surrounding oceans. In order to examine the covarying structure between the Chinese summer rainfall and the large-scale circulation over East Asia, singular value decomposition (SVD) analysis is applied to rainfall and some atmospheric variables such as the $200 \mathrm{hPa}$ zonal wind, $850 \mathrm{hPa}$ horizontal winds, and relative vorticity. The SVD method is useful in identifying the degree of coupling between two meteorological variables [see von Storch and Zwiers (1999) for the detailed methodology].

Figure 2 shows the 1 st coupled modes and their corresponding time series. The explained squared covariances between rainfall and the four atmospheric variables to the total amount are as follows: $65.7 \%$ for zonal wind at $200 \mathrm{hPa}$ (Fig. 2b), $52.3 \%$ for zonal wind at $850 \mathrm{hPa}$ (Fig. 2e), $27.3 \%$ for meridional wind at $850 \mathrm{hPa}$ (Fig. 2h), and $34.2 \%$ for relative vorticity at $850 \mathrm{hPa}$ (Fig. 2k). These largely explained percentages represent the dominant interdecadal changes in the Chinese summer rainfall and its coherent relation with the large-scale circulations in the EASM. Overall, the spatial patterns of summer rainfall show nearly identical structure with each other and they are also consistent with the leading EOF mode of summer rainfall (see Figs. 2a, d, g, and j and compare them with Fig. 1a). Furthermore, the corresponding time series of summer rainfall are also comparable, which represents the regime shift during the late 1970s (dotted lines in Figs. 2c, f, i, and 1).

Before describing the spatial pattern of the four atmospheric variables, the linear correlations between the paired time series are examined first. The time series of the four variables (solid lines in Figs. 2c, f, i, and l) are well correlated with those of rainfall (dotted lines). The correlation of time series between rainfall and the four variables varies from 0.74 to 0.83 , which is significant at the $99 \%$ confidence level.

The paired distribution of the $200 \mathrm{hPa}$ zonal wind shows a southward displacement in the upper tropospheric jet stream from the climatological location over the entire Asian continent (Fig. 2b). This southward displacement of the jet stream should lead an anomalous rising 


\section{SVD $1^{\text {st }}$ mode (1961-1995)}

(a) Precipitation

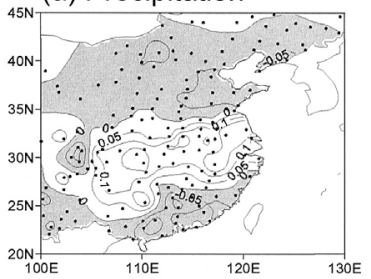

(d) Precipitation

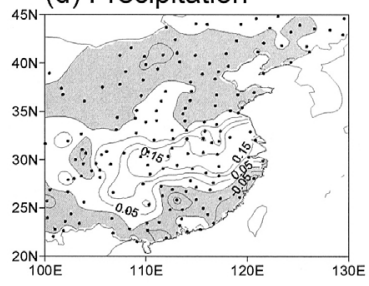

(g) Precipitation
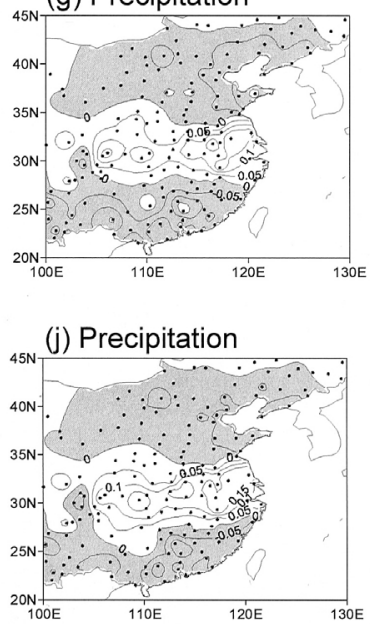

(b) U200

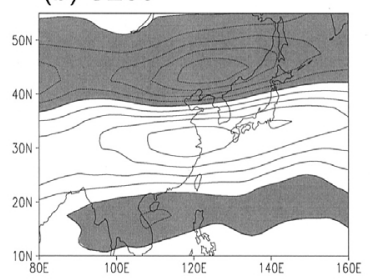

(e) U850

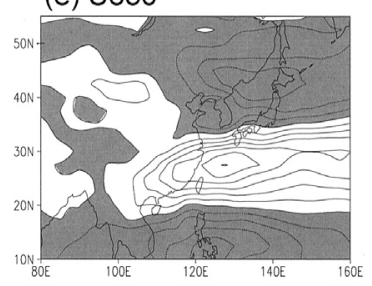

(h) V850

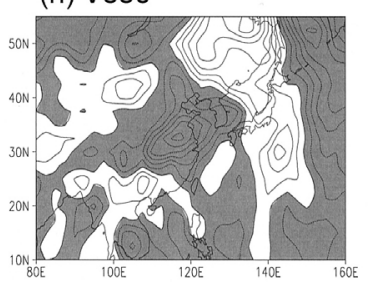

(k) VOR850

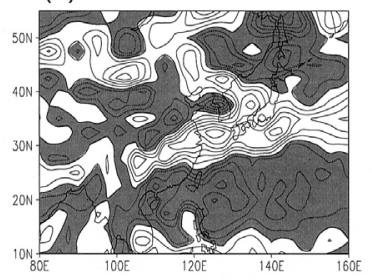

(c) Time series $(65.7 \%)$

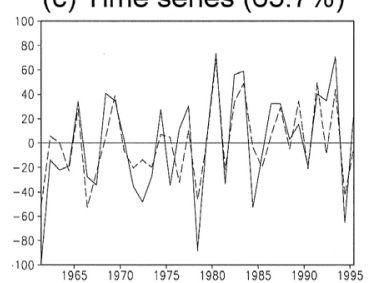

(f) Time series $(52.3 \%)$

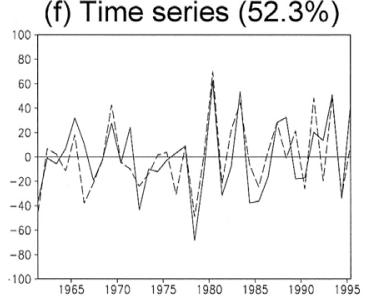

(i) Time series $(27.3 \%)$
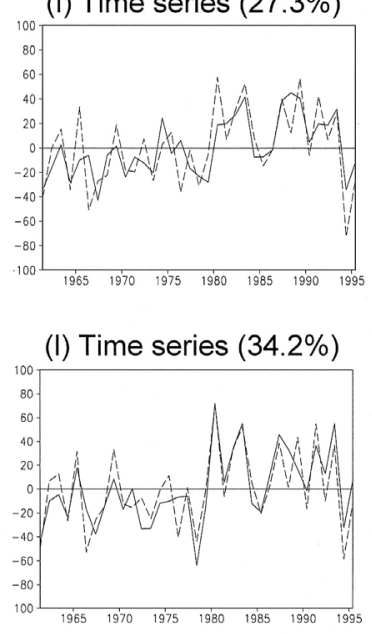

Fig. 2. The leading SVD modes of summer rainfall and the zonal wind at 200 $\mathrm{hPa}(\mathrm{a}-\mathrm{c})$, zonal wind at $850 \mathrm{hPa}(\mathrm{d}-\mathrm{f})$, meridional wind at $850 \mathrm{hPa}$ $(\mathrm{g}-\mathrm{i})$, and relative vorticity at $850 \mathrm{hPa}(\mathrm{j}-\mathrm{l})$. The spatial distributions of paired rainfall and four atmospheric variables are shown in the left panels ( $\mathrm{a}, \mathrm{d}, \mathrm{g}, \mathrm{j})$ and middle panels $(\mathrm{b}, \mathrm{e}, \mathrm{h}, \mathrm{k})$, respectively. Negative values are shaded. Corresponding time coefficients are presented in the right panels $(c, f, i, 1)$. Solid lines denote four atmospheric variables and dotted lines denote rainfall. Units are arbitrary for spatial distributions, $\mathrm{m} \mathrm{s}^{-1}$ and $\mathrm{s}^{-1}$ for solid lines of time coefficients in (c, f, i) and (l), respectively, and $\mathrm{mm} \mathrm{day}^{-1}$ for dotted lines. 
motion along $30^{\circ} \mathrm{N}$ and a sinking motion over north and south of the regions (Liang and Wang 1998; Lau et al. 2000; Gong and Ho 2003). Due to changes in the vertical motion, central China becomes wetter and northern and southern China become drier. It should be noted that the north-south displacement of the upper tropospheric jet stream is closely linked with the march/retreat of the northwestern branch of the North Pacific subtropical high during summer. This is because the air traveling poleward from the subtropical high meets the westerly winds in the midlatitudes. As a result, the strength of the North Pacific subtropical high over East Asia is reduced due to the southward displacement of the upper tropospheric jet stream.

Changes in the summer rainfall can be accounted for by those in the lower tropospheric circulation. The paired zonal and meridional winds at $850 \mathrm{hPa}$ are shown in Figs. 2e, h, respectively. The spatial distribution in the zonal wind shows an increase of westerly wind along $27^{\circ} \mathrm{N}$ and a decrease north and south of the region, showing meridional bands similar to the $200 \mathrm{hPa}$ zonal wind; however, this distribution slightly shifts southward. The paired meridional wind shows the northerly wind over eastern China and the southerly wind, southeast of Japan. The horizontal wind fields represent enhanced cyclonic circulation over East Asia in relation with the spatial pattern of rainfall. In this condition, the southerly monsoon flow over eastern China becomes weaker, i.e., the EASM is almost normal or weak and the flood dominates over the middle-lower Yangtze River valley. This result is consistent with the comments of Zhu and Wang (2002). For a more comprehensive discussion associated with the spatial distribution of rainfall, SVD analysis between summer rainfall and the $850 \mathrm{hPa}$ relative vorticity is performed (Figs. $2 \mathrm{j}, \mathrm{k}$, and $\mathrm{l}$ ). The spatial distribution of the paired relative vorticity at $850 \mathrm{hPa}$ shows a dynamically consistent relation with the rainfall pattern, which also shows a meridionally banded structure. The regions showing increased (decreased) low-level relative vorticity over China are well matched with those showing increased (decreased) rainfall.

Thus, changes in all atmospheric variables analyzed in this study are consistent with those observed in the Chinese summer rainfall. The interdecadal changes in the Chinese summer rainfall are not a local phenomenon, but are coupled with changes in the large-scale circulation over the Asian continent and the adjacent ocean. Further studies should be undertaken for investigating the relation between rainfall and large-scale circulation by using climate modeling.

\section{DIFFERENCES IN SUMMER RAINFALL BETWEEN 1961 - 79 AND 1980 - 95}

Understanding the details of the impact of large-scale circulations on changes in the Chinese summer rainfall may not be simple. Precipitation is the final product of many complex atmospheric processes such as atmospheric circulation, stability, convection, microphysics, and so on. In the present study, we confine our interest to examining the interdecadal changes in the distribution of rainy events as a function of rain rate and assessing their contribution to summer rainfall.

As indicated in the previous section, the Chinese summer rainfall shows a regime shift during the late 1970s, and a shift in large-scale circulation during the same period is closely related to changes in the summer rainfall. Thus, we divide the data into two periods: earlier decades (1961 - 79) and later decades (1980 - 95). We examined the sensitivity of the results 
caused by the choice of the reference year by changing it from the mid-1970s to the mid-1980s and found that the major results are not significantly affected.

\subsection{Changes in Heavy Rainfall}

The difference in the total summer rainfall between the two periods (rainfall for 1980 - 95 minus that for 1961 - 79) shows, overall, three zonally oriented bands with a recurrent opposite sign over China: a positive anomaly over central China and a negative anomaly over northern and southern China (Fig. 3a). The difference exceeds the $90 \%$ confidence level in many stations, as indicated in the figure. Many stations over central and southern China show a high confidence level. The spatial distribution of the difference resembles the 1st EOF mode (see Fig. 1).

Upon examining the time series of the number of rainy events during summer, we discovered that there is a slight increase (decrease) in the number of rainy days over the increased (decreased) rainfall regions (figure not shown). Although this is consistent with changes in the summer rainfall, it is not statistically significant. This is due to the fact that the total number of rainy events is mostly determined by many light rain showers, while the total rainfall amount is mainly determined by a few pouring rain events.

\section{Difference (1980-1995 minus 1961-1979)}
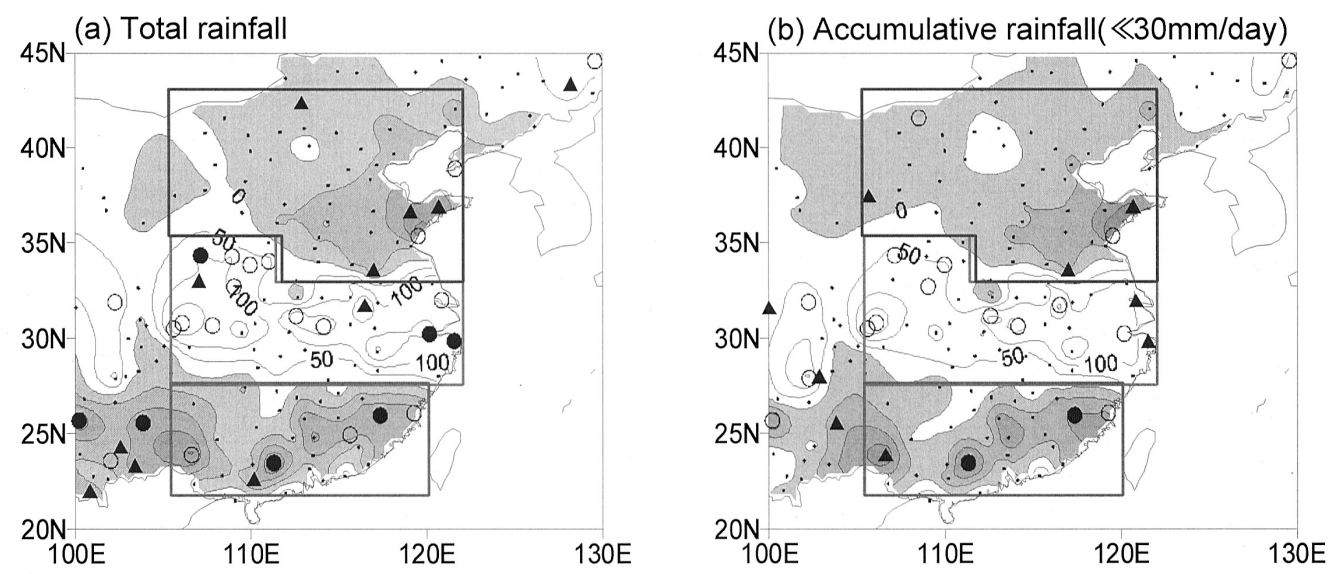

Fig. 3. Difference in the summer rainfall between two decades (1980 - 95 minus 1961 - 79) for (a) total summer rainfall and (b) accumulative rainfall contributed from rain rate $\geq 30 \mathrm{~mm}_{\text {day }}{ }^{-1}$. Open circles are significant at 90\% confidence level; closed circles, 95\%; and closed triangles, 99\%. Negative values are shaded. Contour interval is $50 \mathrm{~mm} 3 \mathrm{month}^{-1}$. 
In order to investigate if there are any significant changes in the total rainfall due to pouring rain events, we show the difference in accumulative rainfall only for a rain rate of more than $30 \mathrm{~mm}_{\text {day }}{ }^{-1}$ between the two decades (Fig. 3b). It should be noted that the two figures (Figs. 3a, b) show a fairly similar spatial distribution and even magnitude. This similarity implies that most of the changes in the total Chinese summer rainfall during the late 1970s can be attributed to heavy rainfall events.

This finding is consistent with the result of Zhai et al. (1999), who emphasized the importance of heavy rainfall events in the long-term variations in Chinese rainfall. However, our results differ from those obtained by Zhai et al. because they analyzed annual precipitation instead of summer precipitation. Their results revealed a significant reduction in rainy days throughout China, even over central China, for the period 1951 - 95. However, our results indicate that the rainy events have not undergone significant changes during the summers during this period for most regions in China.

For a further analysis, we selected three regions, denoted by boxes that roughly cover areas with long-term rainfall anomalies that have the same sign, as shown in Fig. 3. The western boundary of the boxes is set to $105^{\circ} \mathrm{E}$ to avoid the local influence on the rainfall difference due to the elevated mountains. The total number of observed stations is 42,45 , and 29 for the northern, central, and southern regions, respectively. In order to explore changes in daily rainfall characteristics in the regions showing increased rainfall (central China) and those showing decreased rainfall (northern and southern China), the area-mean characteristics of the three regions are examined in the next subsection.

\subsection{Effect of Rain Rate on Summer Rainfall}

Climatologically, during the summer, the amount of rainfall and the number of rainy events over southern China are larger than those of central and northern China. The total rainfall is $818 \mathrm{~mm}$ over southern China and 682 and $507 \mathrm{~mm}$ over central and northern China, respectively. Furthermore, the average number of rainy days over southern, central, and northern China is 47.7, 36.5, and 33.5, respectively. Interestingly, however, the distribution patterns of rainy events with respect to the rain rate for all three regions (left panels of Fig. 4) are fairly similar. For example, rainfall with a daily rain rate of less than $10 \mathrm{~mm}$ occurs on most rainy days, with $64 \%, 58 \%$, and $59 \%$ for northern, central, and southern China, respectively. The frequency decreases rapidly to less than $20 \%$ for a rain rate between 10 and $20 \mathrm{~mm} \mathrm{day}^{-1}$. Approximately $85 \%$ of the rainy events are composed of days with a rain rate of less than $30 \mathrm{~mm}$ day $^{-1}$ in all regions. Rainy events of $\geq 90 \mathrm{~mm} \mathrm{day}^{-1}$ are highly infrequent, accounting for less than $5 \%$ of the total number of events.

The importance of heavy rainfall events in contributing to the total rainfall amount is clearly depicted in the right panels of Fig. 4, which show the expected value of the rainfall amount (rainfall $\times$ frequency) in each rain rate category. While nearly $60 \%$ of the rainy events have a rain rate less than $10 \mathrm{~mm} \mathrm{day}^{-1}$, these events contribute only $12-16 \%$ of the total rainfall (Figs. 4b, d, and f). On the other hand, the rainy events $\geq 10 \mathrm{~mm} \mathrm{day}^{-1}$ contribute more than $80 \%$ to the total rainfall, although their frequency is only about $15 \%$ for all three regions. For rainy events of $30-90 \mathrm{~mm} \mathrm{day}^{-1}$, the contribution drops sharply because of the extremely 
Difference (1980-1995 minus 1961-1979)

(a) Northern China

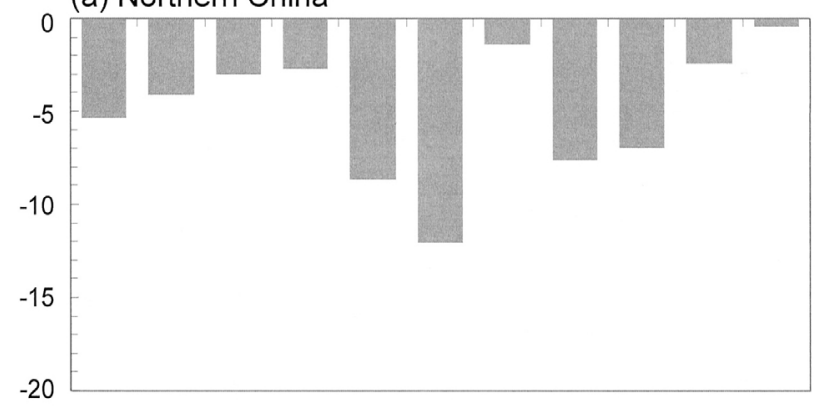

(b) Central China

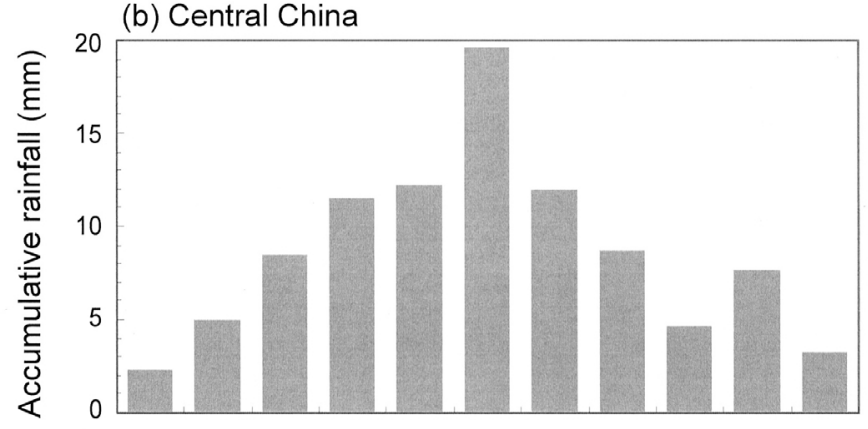

(c) Southern China .

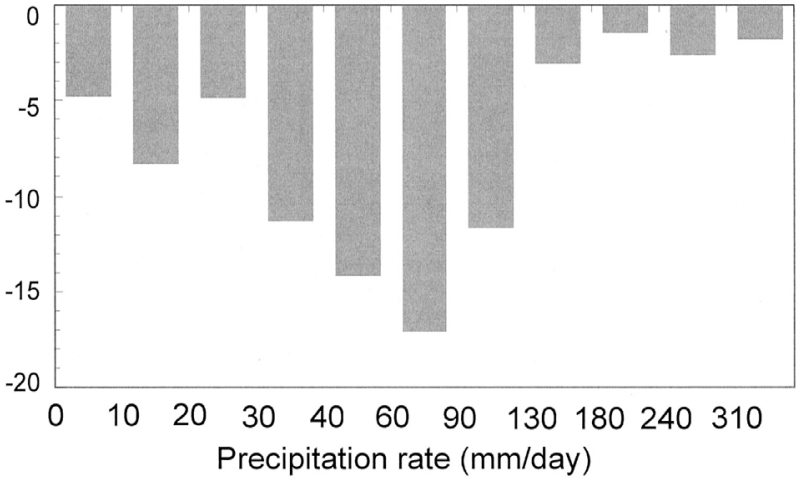

Fig. 4. Contribution of rainfall frequency (a, c, e) and accumulative rainfall (b, $\mathrm{d}, \mathrm{f}$ ) for various thresholds of rain rate (i.e., 0.1 - 10, 10 - 20, 20 - 30, 30 - 40, 40 - 60, 60 - 90, 90 - 130, 130 - 180, 180 - 240, 240 - 310, and greater than $310 \mathrm{~mm} \mathrm{day}^{-1}$ ), respectively, to the total number of rainy days (left column) and the total rainfall amount (right column) during summer. 
low incidence of such events. However, the rainfall contributed by these rain events is about $40 \%$ of the total rainfall. The extreme rainy events $\geq 90 \mathrm{~mm} \mathrm{day}^{-1}$, which occur about once each summer, contribute about $20 \%$ to total rainfall.

The difference in the summer rainfall between the two decades, when averaged over all stations within the three boxes shown in Fig. 3, indicates rainfall reductions of $55 \mathrm{~mm}$ and $81 \mathrm{~mm}$ over northern and southern China, respectively, and an enhancement of $95 \mathrm{~mm}$ over central China during the later decades as compared to the earlier period. In order to investigate the contribution in terms of the function of rain rate in the regions, the difference in accumulative rainfall attributed to each threshold of rain rate is shown in Fig. 5. Over northern China (Fig. 5a), the accumulative rainfall from all categories has decreased during the decades since 1980, with the major changes of $40-90 \mathrm{~mm}_{\text {day }}{ }^{-1}$ and $130-240 \mathrm{~mm}_{\text {day }}{ }^{-1}$ in the rain rate. These changes account for nearly $70 \%$ of the difference of the total rainfall. Over central and southern China, the important contribution of rainy events with a rain rate of $30-180 \mathrm{~mm}_{\text {day }^{-1}}$ is fairly evident (Figs. $5 \mathrm{~b}, \mathrm{c}$ ). The contribution of a rain rate of $<30 \mathrm{~mm} \mathrm{day}^{-1}$ to total rainfall is negligible in all regions.

The above results indicate that the interdecadal changes during the late 1970s possibly correspond to the intensity of heavy rainfall. Although this conclusion is easily expected, it is not definite because there is no objective measure to categorize the rainy events into light, heavy, and very heavy ones. The daily rain rate exceeding a specific threshold is generally used (e.g., Zhai et al. 1999, used $50 \mathrm{~mm}^{\text {day }}{ }^{-1}$ ), but the threshold is not suitable for each study. Therefore, we suggest a more suitable category that uses the accumulative rainfall frequency (f) rather than the daily rain rate, although the latter is more substantial. The categories of rainfall are established as follows: light rain ( $\mathrm{f} \leq 80 \%)$, heavy rain $(80 \%<\mathrm{f} \leq 95 \%)$, and very heavy rain ( $\mathrm{f}>95 \%$ ). That is, after sorting all the rainy events during the period of the analysis in order from the lightest rainy event to the heaviest one, we first define the lowest $80 \%$ of them as light rain; the next $15 \%$, heavy rain, and then the remainder (5\%), very heavy rain, which roughly makes the three rainfall categories contribute equally to total summer rainfall as shown in the third column of Table 1. Table 1 summarizes the contribution of collocated rain rate to the climatology and the difference between the earlier and the later decades by applying $\mathrm{f}$. Over the three regions, the approximate maximum rain rate for light and heavy rain corresponds to $\sim 25 \mathrm{~mm} \mathrm{day}^{-1}$ and $\sim 70 \mathrm{~mm} \mathrm{day}^{-1}$, respectively, i.e., rain rate $0.1-\sim 25 \mathrm{~mm} \mathrm{day}^{-1}$ includes $80 \%$ of the total rainy events. While the light rainy events account for $30-35 \%$ of total Chinese summer rainfall, they contribute only $15-20 \%$ to the difference. However, the heavy and very heavy rainy events explain more than $80 \%$ of the difference. Thus, it can be concluded that most of the interdecadal changes in Chinese summer rainfall are due to the increased intensity of heavy and very heavy rain during the later decades (1980 - 95).

\section{DISCUSSIONS AND SUMMARY}

This study evaluates interdecadal changes in the total rainfall amount and rainfall intensity over China during the northern summer for the period 1961 - 95. Summer rainfall decreased by about $10 \%$ over northern and southern China but increased by about $15 \%$ over central 


\section{Climatology (1961-1995)}

\section{Northern China}

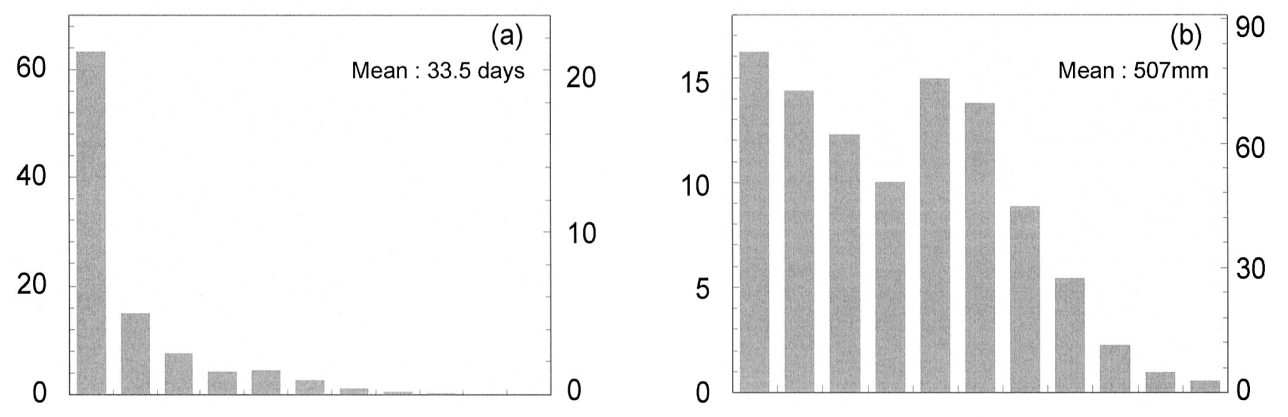

\section{Central China}

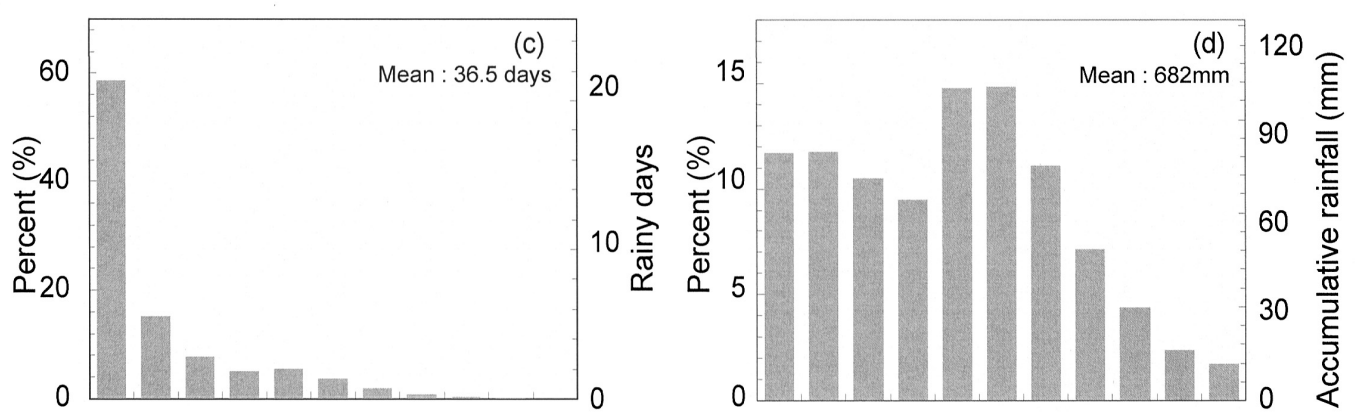

Southern China
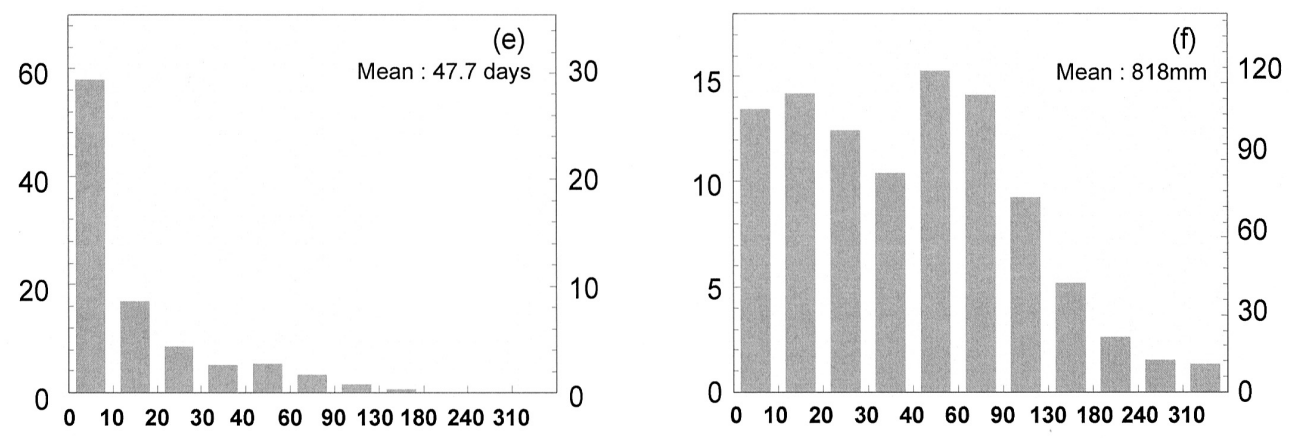

Precipitation rate ( $\mathrm{mm} /$ day)

Fig. 5. Same as in Fig. 4 with the exception of the difference (1980 - 95 minus 1961 - 79) in rainfall contribution. 
Table 1. Contribution of accumulative rainfall from light rain (accumulative rainfall frequency $f \leq 80 \%)$, heavy rain $(80 \%<f \leq 95 \%)$, and very heavy rain $(f>95 \%)$ to the total summer rainfall for the $1961-95$ climatology and the difference between the earlier (1961 - 79) and later decades (1980 - 95) over three regions.

\begin{tabular}{|c|c|c|c|}
\hline Region & Category & $\begin{array}{l}\text { Contribution to total } \\
\text { summer rainfall (\%) }\end{array}$ & $\begin{array}{l}\text { Contribution to the } \\
\text { difference }(\%)\end{array}$ \\
\hline \multirow{4}{*}{ Northern China } & Light rain & 33 & 18 \\
\hline & Heavy rain & 35 & 25 \\
\hline & Very heavy rain & 32 & 57 \\
\hline & Total & $100(507 \mathrm{~mm} /$ summer $)$ & $100(-55 \mathrm{~mm} / \mathrm{summer})$ \\
\hline \multirow{4}{*}{ Central China } & Light rain & 31 & 14 \\
\hline & Heavy rain & 35 & 39 \\
\hline & Very heavy rain & 34 & 47 \\
\hline & Total & $100(682 \mathrm{~mm} /$ summer $)$ & $100(95 \mathrm{~mm} / \mathrm{summer})$ \\
\hline \multirow{4}{*}{ Southern China } & Light rain & 35 & 20 \\
\hline & Heavy rain & 34 & 36 \\
\hline & Very heavy rain & 31 & 44 \\
\hline & Total & $100(818 \mathrm{~mm} / \mathrm{summer})$ & $100(-81 \mathrm{~mm} /$ summer $)$ \\
\hline
\end{tabular}

China along the Yangtze River valley during the later decades (1980 - 95) as compared to the earlier decades (1961 - 79). Although the corresponding changes in the number of rainy events are consistent with those in the summer rainfall, its significance is very low. It is found that most of the variations in rainfall are accounted for by those in rainy events $\left(\geq \sim 30 \mathrm{~mm} \mathrm{day}^{-1}\right)$. In particular, over central China, the accumulative rainfall contributed by a rain rate of $30-180 \mathrm{~mm} \mathrm{day}^{-1}$ accounts for about $70 \%$ of the interdecadal difference. There is a significant decrease in accumulative rainfall in the $30-240 \mathrm{~mm} \mathrm{day}^{-1}$ range over northern and southern China, accounting for about $75 \%$ of the interdecadal rainfall anomaly. The results indicate that long-term variations in the frequency of rainy events greater than $30 \mathrm{~mm} \mathrm{day}^{-1}$ are significant, while variations in the number of rainy events are constant. 
Changes in the total rainfall amount and rainfall intensity found in the present study are consistent with those obtained by previous studies that examined changes in the EASM. Chen et al. (1992) found that the strength of the monsoon circulation over North China has considerably reduced. Kaiser (2000) also found that the total cloud amount has decreased in particular over northeastern China. Accordingly, there is a decreasing trend in low-level convergence over northern China and an increasing trend in low-level convergence over central China (see Fig. 2k). Besides the lower tropospheric convergence, the horizontal wind and the upper tropospheric zonal wind also present apparent interdecadal changes associated with the Chinese summer rainfall during the late 1970s. The relationships of these coherent rainfall-atmospheric variables are examined using SVD analysis and are described in Fig. 2.

The present study suggests that most of the interdecadal changes that occurred during the late 1970s are attributed to extreme rainy events. Thus, there might be significant short-timescale changes in the EASM circulations, such as frequency and intensity of the synoptic-scale disturbances and typhoon activity. Interestingly, Ho et al. (2003) suggested that the desertification over northern China leads to stronger and weaker convective activity over central and northern China, respectively. On the other hand, it is apparent that a significant transition in the northern spring sea surface temperatures over the equatorial Pacific is primarily responsible for the interdecadal changes in the Chinese summer rainfall through the strengthening and southward shift of the North Pacific subtropical high (Gong and Ho 2002). An increase in the number of extreme events implies the higher potential of severe floods, although the interdecadal rainfall anomalies may be small compared to the seasonal mean. Further research is required to unravel the possible causes and consequences of extreme events in long-term climate changes.

Acknowledgements This study was supported by the evolution of Asian monsoon project in Korea Ocean Research and Development Institute (PG05020). The clarity of the paper has been significantly improved due to suggestions made by Prof. Jen-Ping Chen and two anonymous reviewers.

\section{REFERENCES}

Chen, L., M. Dong, and Y. Shao, 1992: The characteristics of interannual variations on the East Asian monsoon. J. Meteor. Soc. Japan, 70, 397-421.

Gong, D. Y., and C. H. Ho, 2002: Summer rainfall shift over Yangtze River valley in the late 1970s. Geophys. Res. Lett., 29, 10.1029/2001GL014523.

Gong, D. Y., and C. H. Ho, 2003: Arctic Oscillation signals in the East Asian summer monsoon. J. Geophys. Res., 108, doi:10.1029/2002JD002193.

Kaiser, D. P., 2000: Decreasing cloudiness over China: An updated analysis examining additional variables. Geophys. Res. Lett., 27, 2193-2196.

Kun, Y., 2005: Flood emergency management in China. ICID 21st European Regional Conference on Integrated Land and Water Resources and Water Resources Management: Towards Sustainable Rural Development, Frankfurt(Oder) and Slubice, Germany and 
Poland, ICID, 15-19 May 2005. [Available online at http:// www.zalf.de/icid/ ICID_ERC2005/HTML/ERC2005PDF/Topic_2/Kun_Yang.pdf]

Ho, C. H., J. Y. Lee, M. H. Ahn, and H. S. Lee, 2003: A sudden change in summer rainfall characteristics in Korea during the late 1970s. Inter. J. Climatol., 23, 117-128.

Lau, K. M., K. M. Kim, and S. Yang, 2000: Dynamical and boundary forcing characteristics of regional components of the Asian summer monsoon. J. Climate, 13, 2461-2482.

Li, C., J. He, and J. Zhu, 2004: A review of decadal/interdecadal climate variation studies in China. Adv. Atmos. Sci., 21, 425-436.

Liang, X. Z, and W. C. Wang, 1998: Association between China monsoon rainfall and tropospheric jets. Quart. J. Roy. Meteor. Soc., 124, 2597-2623.

Nitta, T., and Z. Z. Hu, 1996: Summer climate variability in China and its association with $500 \mathrm{hPa}$ height and tropical convection. J. Meteor. Soc. Japan, 74, 425-445.

Shen, S., and K. M. Lau, 1995: Biennial oscillation associated with the East Asian summer monsoon and tropical sea surface temperatures. J. Meteor. Soc. Japan, 73, 105-124.

Uppala, S., 2002: ECMWF reanalysis, 1957-2001, ERA-40. ERA-40 Project Report Series, 3, $1-10$.

Von Storch, H., and F. W. Zwiers, 1999: Statistical analysis in climate research, Cambridge Univ. press, $484 \mathrm{pp}$.

Wang, S. W., J. H. Zhu, and J. N. Cai, 2004: Interdecadal variability of temperature and precipitation in China since 1980. Adv. Atmos. Sci., 21, 307-313.

Weng, H., K. M. Lau, and Y. Xue, 1999: Multi-scale summer rainfall variability over China and its long-term link to global sea surface temperature variability. J. Meteor. Soc. Japan, 77, 1-13.

Xue, Y., 1996: The impact of desertification in the Mongolian and the inner Mongolian grassland on the regional climate. J. Climate, 9, 2173-2189.

Yatagai, A., and T. Yasunari, 1994: Trends and decadal-scale fluctuations of surface air temperature and precipitation over China and Mongolia during the recent 40 year period (1951 - 1990). J. Meteor. Soc. Japan, 72, 937-957.

Yoo, S. H., C. H. Ho, S. Yang, H. J. Choi, and J. G. Jhun, 2004: Influences of tropical western and extratropical Pacific SST on East and Southeast Asian climate in the summers of 1993-94. J. Climate, 17, 2673-2687.

Zhai, P., A. Sun, and F. Ren, 1999: Changes in climate extremes in China. Climatic Change, 42, 203-218.

Zhu, J., and S. Wang, 2002: 80 yr oscillation of summer rainfall over North China and East Asian summer monsoon. Geophys. Res. Lett., 29, 10.1029/2001GL013997. 